\title{
Qualidade de produto minimamente processado à base de abóbora, cenoura, chuchu e mandioquinha-salsa
}

\author{
Maintenance of the quality of fresh-cut products made up of pumpkin, \\ carrot, chayote, and arracacha (peruvian carrot)
}

\author{
Juliana Alvarenga ALVES ${ }^{1 \star}$, Eduardo Valério de Barros VILAS BOAS ${ }^{1}$, \\ Brígida Monteiro VILAS BOAS ${ }^{2}$, Éllen Cristina de SOUZA ${ }^{3}$
}

\begin{abstract}
Resumo
O objetivo deste trabalho foi avaliar a qualidade de produto minimamente processado, à base de quatro hortaliças - abóbora, cenoura, chuchu e mandioquinha-salsa, armazenado a $5^{\circ} \mathrm{C}$ por 8 dias. Observou-se que os teores de umidade, fibra, proteína, cinza e fração glicídica das quatro hortaliças não foram afetados pelo tempo de armazenamento, entretanto o teor de extrato etéreo aumentou. Durante o armazenamento, o teor de vitamina $\mathrm{C}$ e de acidez titulável diminuiu em todas as hortaliças. $\mathrm{O}$ teor de $\beta$-caroteno do chuchu não alterou, entretanto, aumentou na abóbora, na cenoura e na mandioquinha-salsa. $\mathrm{O}$ pH das quatro hortaliças aumentou com o armazenamento. Os teores de sólidos solúveis da cenoura e da mandioquinha-salsa aumentaram, não sendo afetados na abóbora e no chuchu. As notas de aparência do "mix" não foram inferiores a 7 (gostei moderadamente), durante o armazenamento. Os coliformes a $35^{\circ} \mathrm{C}$ presentes no "mix" aumentaram e não foi constatada a presença de coliformes a $45^{\circ} \mathrm{C}$ e Salmonella sp. em nenhum tempo avaliado. Conclui-se que a vida útil, entendida sob os aspectos nutricionais, sensoriais e microbiológicos, pode ser estabelecida em 8 dias sob refrigeração para abóbora, cenoura, chuchu e mandioquinha-salsa submetidos ao processamento mínimo.
\end{abstract}

Palavras-chave: abóbora; cenoura; chuchu; mandioquinha-salsa; processamento mínimo; vida útil.

\begin{abstract}
The goal of this study was to evaluate the quality of fresh-cut products made up of four vegetables: pumpkin, carrot, chayote, and arracacha (peruvian carrot) stored at $5{ }^{\circ} \mathrm{C}$ for 8 days. It was observed that the contents of humidity, fiber, protein, ash, and glucidic fraction of the four vegetables were not affected by the time of storage; however, the content of ethereal extract increased. During storage, the content of vitamin $\mathrm{C}$ and titratable acidity decreased in all the vegetables. The content of $\beta$-carotene of chayote did not change, whereas the content in the pumpkin, carrot, and the peruvian carrot increased. The $\mathrm{pH}$ of the four vegetables increased during storage. The contents of soluble solid of the carrot and the peruvian carrot increased, but they were not affected for the pumpkin and chayote. The "mix" appearance ratings were not lower than 7 (liked moderately) during storage showing product acceptance by the panelists. The coliforms at $35^{\circ} \mathrm{C}$ present in the mix increased during storage. No coliforms at $45^{\circ} \mathrm{C}$ and Salmonella sp. in were observed in the period of time studied. It can be said that, according to microbiological, sensorial, and nutritional aspects, the shelf-life of minimally processed pumpkin, carrot, chayote, and peruvian carrot is 8 days under refrigeration.
\end{abstract}

Keywords: pumpkin; carrot; chayote; peruvian carrot; minimal processing; shelf life.

\section{Introdução}

No Brasil, embora haja grande disponibilidade de produtos hortícolas acessíveis à substancial parcela da população, observam-se níveis inaceitáveis de perdas destes produtos devido a técnicas inadequadas adotadas desde a colheita até o armazenamento. Assim, o processamento mínimo de frutas e hortaliças pode contribuir com a redução de desperdícios, além de possibilitar maior praticidade e economia de tempo no preparo diário de alimentos, cada vez mais necessários ao agitado mundo moderno.

Segundo a Associação Internacional dos Produtos Minimamente Processados (INTERNACIONAL..., 2007), produtos minimamente processados (fresh cut, levemente processados ou parcialmente processados) são definidos como qualquer fruta ou hortaliça, ou ainda qualquer combinação delas, que foi alterada fisicamente a partir de sua forma original, embora mantenha seu estado fresco. As frutas e as hortaliças são selecionadas, lavadas, descascadas e cortadas, resultando num produto $100 \%$ aproveitável que, posteriormente, é embalado no intuito de oferecer aos consumidores frescor, conveniência e qualidade nutricional.

As hortaliças têm importante papel na alimentação humana, principalmente por serem excelentes fontes de

Recebido para publicação em 14/6/2008

Aceito para publicação em 7/7/2009 (003475)

${ }^{1}$ Departamento de Ciência dos Alimentos, Universidade Federal de Lavras - UFLA, CP 3037, CEP 37200-000, Lavras - MG, Brasil, E-mail: juliana_alvarenga@yahoo.com.br

${ }^{2}$ Instituto Federal de Educação, Ciência e Tecnologia do Sul de Minas, Campus Machado, Rod. Machado - Paraguaçu, Km 3, Bairro Santo Antônio, CEP 37750-000, Machado - MG, Brasil

${ }^{3}$ Universidade Federal do Mato Grosso - UFMT, Campus I Uniaraguaia, CEP 78698-000, Pontal do Araguaia - MT, Brasil

${ }^{*}$ A quem a correspondência deve ser enviada 
vitaminas, minerais e fibra dietária e por conterem em sua composição diferentes grupos de substâncias químicas que atuam no organismo humano, reduzindo os riscos de doenças cardiovasculares, e podem atuar como potentes agentes anticancerígenos, dentre outras importantes funções no organismo. Assim, o "mix" de hortaliças, composto por abóbora, cenoura, chuchu e mandioquinha-salsa, torna-se promissor, pelo fato desse produto apresentar características benéficas para o consumidor, facilitando o acesso a produtos vegetais com diferentes teores nutricionais, além de reduzir o tempo de preparo de refeições e requerer menos espaço para seu armazenamento e transporte.

Apesar do alto valor nutritivo, o consumo da abóbora (Cucurbita moschata Duch) só não é maior devido ao grande tamanho dos frutos e a dificuldade no descascamento, tornando seu preparo muito trabalhoso. Por isso, a oferta desse produto na forma minimamente processada é uma alternativa interessante para o mercado (SASAKI et al., 2006). A cenoura (Daucus carota L.) é a principal fonte de origem vegetal em carotenoides provitamínicos $\mathrm{A}$, especialmente o $\alpha$ e o $\beta$-caroteno que podem ser transformados em vitamina A no organismo humano (LIMA et al., 2001).

O chuchu (Sechium edule Swartz.) é fonte de vitaminas, sais minerais e aminoácidos livres, de bom valor energético e excelente qualidade de fibras, é recomendado particularmente para pessoas que estão sob dietas e que precisam de um alimento de boa digestão (LOPES et al., 1994). A mandioquinha-salsa (Arracacia xanthorrhiza Bancroft) faz parte do importante grupo de alimentos considerados energéticos, ou seja, alimentos ricos em carboidratos. É bastante rica em cálcio, fósforo e niacina, de digestão fácil e por isso mesmo especialmente recomendada na alimentação de crianças, pessoas idosas e convalescentes (SANTOS et al., 1993).

De um modo abrangente, a qualidade do produto vegetal pode ser definida como o "[...]conjunto de características que diferenciam componentes individuais de um mesmo produto e que têm significância na determinação do grau de aceitação desse produto pelo consumidor[...]". Dessa forma devem ser considerados os atributos sensoriais (aparência, textura, sabor, aroma); o valor nutricional (carboidratos, proteínas, lipídios, vitaminas, minerais) e a segurança (microrganismos patogênicos ao homem, substâncias naturais tóxicas) (CHITARRA, M. I. F.; CHITARRA, A. B., 2005).

As combinações de produtos cortados higienicamente, procedimentos rigorosos de sanificação, embalagens apropriadas e baixas temperaturas durante o processamento e distribuição, não apenas favorecem a qualidade sensorial das frutas e hortaliças minimamente processadas, mas também ajudam a minimizar os riscos microbiológicos (CANTWELL; SUSLOW, 2002).

O presente trabalho teve por objetivo avaliar a qualidade do "mix" de hortaliças minimamente processadas, composto por abóbora, cenoura, chuchu e mandioquinha-salsa durante o armazenamento sob refrigeração, por meio de análises físicas, químicas, sensoriais e microbiológicas.

\section{Material e métodos}

\subsection{Matéria-prima}

As hortaliças (abóbora, cenoura, chuchu e mandioquinhasalsa) foram provenientes das Centrais de Abastecimento de Minas Gerais S/A (CEASA-MG), Contagem, MG e adquiridas no mercado local de Lavras - MG, com ausência de injúrias físicas. Em seguida, foram transportadas para o Laboratório de Pós-colheita de Frutas e Hortaliças do Departamento de Ciência dos Alimentos (DCA) da Universidade Federal de Lavras - UFLA, Lavras - MG.

\subsection{Processamento mínimo das hortaliças}

Todo o processamento mínimo foi realizado em condições normais de higiene. As hortaliças foram lavadas em água corrente com detergente neutro e sanificadas em hipoclorito de sódio $200 \mathrm{mg} . \mathrm{L}^{-1}$ por 5 minutos. Em seguida, foram descascadas manualmente com o auxílio de facas afiadas, e os pedaços foram cortados em dimensões de aproximadamente $2 \times 2 \times 1 \mathrm{~cm}$ utilizando-se um processador Master-AT. O produto minimamente processado foi sanificado em hipoclorito de sódio $50 \mathrm{mg} . \mathrm{L}^{-1}$ por 3 minutos e, em seguida, apenas as mandioquinhassalsa foram imersas em solução de ácido ascórbico $1 \%$ por 2 minutos. As hortaliças foram colocadas em peneira plástica para retirada do excesso de líquido por 2 minutos. Os pedaços de abóbora, cenoura, chuchu e mandioquinha-salsa foram misturados em proporções semelhantes e, em seguida, foram acondicionados (aproximadamente $400 \mathrm{~g}$ ) em embalagens flexíveis de polietileno de baixa densidade linear $(25 \times 20 \mathrm{~cm})$ com taxa de permeabilidade para $\mathrm{O}_{2} 1700 \mathrm{~cm}^{3} / \mathrm{m}^{2}$ dia. Estas embalagens foram seladas em seladora a vácuo modelo AP450 - Tecmaq, armazenadas em câmara-fria a $5{ }^{\circ} \mathrm{C} \pm 1$ (UR 90\% \pm 5$)$ por 8 dias, e as análises foram realizadas a cada 2 dias.

As embalagens contendo o "mix" foram retiradas de $2 \mathrm{em}$ 2 dias da câmara fria para avaliação da composição centesimal, acidez titulável, $\mathrm{pH}$, sólidos solúveis, vitamina $\mathrm{C}$ e $\beta$-caroteno para cada hortaliça individualmente e as análises sensoriais e microbiológicas foram realizadas para o "mix" a cada 2 e 4 dias, respectivamente.

\subsection{Análises químicas}

\section{Composição centesimal}

Umidade (g.100 g $\mathrm{g}^{-1}$ ) - as hortaliças foram previamente trituradas em liquidificador e a umidade foi determinada segundo a técnica gravimétrica, com emprego de calor em estufa ventilada à temperatura de $65^{\circ} \mathrm{C}$, até obtenção de peso constante, segundo a AOAC (ASSOCIATION..., 2005).

Extrato etéreo (g.100 g-1 de matéria integral) - a determinação foi realizada por extração com solvente orgânico (éter etílico) em aparelho extrator do tipo Soxhlet, segundo método da AOAC (ASSOCIATION..., 2005).

Proteína bruta (g. $100 \mathrm{~g}^{-1}$ de matéria integral) - por meio do teor de nitrogênio por destilação em aparelho de Microkjedahl (semimicro), usando o fator 6,25, procedeu-se ao cálculo do teor de proteína bruta, conforme procedimento da AOAC (ASSOCIATION..., 2005). 
Fibra bruta (g.100 g ${ }^{-1}$ de matéria integral) - a determinação foi feita por hidrólise ácida, pelo método gravimétrico, segundo o método descrito por von de Kamer e van Ginkel (1952).

Fração cinzas ou resíduo mineral fixo (g.100 g $\mathrm{g}^{-1}$ de matéria integral) - determinou-se gravimetricamente, avaliando a perda de peso do material submetido ao aquecimento em mufla a $550-660{ }^{\circ} \mathrm{C}$ (ASSOCIATION..., 2005).

Fração glicídica ou extrato não nitrogenado $\left(\mathrm{g} .100 \mathrm{~g}^{-1} \mathrm{de}\right.$ matéria integral) - Calculou-se a fração glicídica pela diferença segundo a equação: \% Fração Glicídica = 100 - (\% umidade + $\%$ extrato etéreo + \% proteína bruta $+\%$ fibra bruta $+\%$ fração cinzas), considerando a matéria integral.

\section{Acidez titulável (\% ácido málico)}

Realizada por titulação com solução de $\mathrm{NaOH} 0,01 \mathrm{~N}$, tendo como indicador fenolftaleína (INSTITUTO..., 1985).

$p H$

Utilizou-se pHmetro TECNAL (Tec 3MP), segundo a AOAC (ASSOCIATION..., 2005).

\section{Sólidos solúveis ( ${ }^{\circ}$ Brix)}

Usou-se refratômetro digital ATAGO PR-100, com compensação de temperatura automática a $25^{\circ} \mathrm{C}$ (ASSOCIATION..., 2005).

As avaliações de acidez titulável, pH e sólidos solúveis foram feitas em homogenato filtrado, após trituração das hortaliças individuais em homogeneizador de tecidos, na proporção 1:5 (hortaliça: água).

\section{$\beta$-caroteno ( $\left.m g .100 \mathrm{~g}^{-1}\right)$}

Extraído com acetona: hexano (4:6) e determinado segundo Nagata e Yamashita (1992), após o seu equacionamento:

$\beta$-caroteno $=0,216 \mathrm{~A}_{663}-1,22 \mathrm{~A}_{645}-0,304 \mathrm{~A}_{505}+0,452 \mathrm{~A}_{453}$, sendo: $A_{663}, A_{645}, A_{505}$ e $A_{453}$, leituras de absorbância nos respectivos comprimentos de onda.

\section{Vitamina C total ( $m g$ de ácido ascórbico. $100 \mathrm{~g}^{-1}$ de polpa)}

O teor de ácido ascórbico (após a oxidação a ácido deidroascórbico ) foi determinado pelo método colorimétrico, utilizando-se 2,4-dinitrofenil-hidrazina, segundo Strohecker e Henning (1967).

\subsection{Análises microbiológicas}

Coliformes a 35 e $45^{\circ} \mathrm{C}\left(\mathrm{NMP}^{-1}\right.$ de polpa) e pesquisa de Salmonella sp. foram realizadas no Laboratório de Microbiologia de Alimentos do DCA/UFLA, de acordo com o Downes e Ito (2001). A presença de Escherichia coli foi confirmada com a inoculação de alíquotas dos tubos positivos para coliformes a $45^{\circ} \mathrm{C}$ em placas contendo ágar eosina azul de metileno (EMB). Foram consideradas positivas as colônias típicas com coloração verde brilhante.

\subsection{Análise sensorial}

A análise sensorial foi feita usando o Teste Qualitativo Afetivo em que se avaliou o quanto a pessoa gostou ou desgostou da aparência do "mix", utilizando-se uma escala hedônica estruturada mista, de nove pontos, a saber: 1 - desgostei extremamente; 2 - desgostei muito; 3 - desgostei moderadamente; 4 - desgostei ligeiramente; 5 - não gostei/ nem desgostei; 6 - gostei ligeiramente; 7 - gostei moderadamente; 8 - gostei muito; e 9 - gostei muitíssimo.

Ao mesmo tempo foi realizado também o teste de aceitabilidade do produto (intenção de compra), utilizando-se uma escala de intenção de compra estruturada mista de cinco pontos, a saber: 1 - certamente não compraria; 2 - provavelmente não compraria; 3 - talvez compraria/talvez não compraria; 4 - provavelmente compraria; e 5 - certamente compraria. Os testes foram realizados com 30 provadores diferentes a cada intervalo de análise. Usou-se uma embalagem exclusiva para a análise sensorial.

\subsection{Delineamento experimental e análise estatística}

$\mathrm{O}$ delineamento utilizado para as análises químicas foi o inteiramente casualizado, com 4 repetições, em que os tratamentos foram constituídos por cinco tempos de armazenamento $(0,2,4$, 6 e 8 dias). O delineamento estatístico utilizado para a avaliação sensorial foi em blocos casualizados, em que cada provador constituiu um bloco (100 blocos). A parcela experimental foi constituída por uma embalagem, contendo cerca de $400 \mathrm{~g}$ do produto minimamente processado. As análises estatísticas foram feitas com auxílio do programa Sisvar (FERREIRA, 2000).

\section{Resultados e discussão}

A composição química centesimal de um alimento expressa o seu potencial em nutrientes, sendo esses dados importantes para a indústria de alimentos. Na literatura, são escassas as informações sobre a composição centesimal de hortaliças minimamente processadas.

Os teores de umidade, fibra, proteína, cinza e fração glicídica da abóbora, cenoura, chuchu e mandioquinha-salsa não foram afetados significativamente $(\mathrm{p}>0,05)$ pelo tempo de armazenamento. Os teores médios da composição centesimal, com exceção do extrato etéreo das quatro hortaliças estão apresentados na Tabela 1. Estes valores estão em conformidade com os citados pela Tabela de Composição de Alimentos (UNIVERSIDADE..., 2001). Os resultados também estão de acordo com os encontrados por Pilon (2003), no qual o tempo de armazenamento não afetou consideravelmente a composição centesimal de cenouras minimamente processadas.

Segundo Chitarra, M. I. F. e Chitarra, A. B. (2005), os componentes mais abundantes em hortícolas são a água e os carboidratos, não sendo esses produtos, em geral, boas fontes de lipídios e nem proteínas. Isso pôde ser verificado neste trabalho, considerando que a somatória do valor médio dos teores de água e carboidratos em abóbora, cenoura, chuchu e mandioquinha-salsa constitui, aproximadamente, $97 \%$ da composição do alimento.

O tempo de armazenamento influenciou significativamente $(\mathrm{p}<0,01)$ o teor de extrato etéreo, que aumentou nas quatro hortaliças estudadas (Figura 1a, b, c, d). 
As variáveis acidez titulável e $\mathrm{pH}$ foram afetadas significativamente $(\mathrm{p}<0,01)$ pelo tempo de armazenamento em abóbora, cenoura, chuchu, e mandioquinha-salsa minimamente processados. Pode-se observar que a abóbora, a cenoura, o chuchu e a mandioquinha-salsa tiveram seus valores de acidez titulável decrescidos (Figura 2a, b, c, d).

A acidez em produtos hortícolas é atribuída, principalmente, aos ácidos orgânicos que se encontram dissolvidos nos vacúolos das células, tanto na forma livre, como combinada com sais, ésteres, glicosídeos, etc. (CHITARRA, M. I. F.; CHITARRA, A. B., 2005). O teor de ácidos orgânicos tende a diminuir durante o processo de oxidação dos ácidos no ciclo dos ácidos tricarboxilícos em decorrência do processo de respiração (BRODY, 1996).

Segundo Nunes et al. (2005), o teor de acidez titulável da mandioquinha-salsa minimamente processada não alterou durante o armazenamento, mantendo um valor médio de $0,13 \%$ de ácido málico. Valor esse, próximo ao encontrado neste trabalho, que foi em média $0,117 \%$ de ácido málico.

Tabela 1. Composição centesimal ${ }^{1}$ das quatro hortaliças minimamente processadas armazenadas a $5{ }^{\circ} \mathrm{C} \pm 1$ (UR 90\% \pm 5$)$ por 8 dias.

\begin{tabular}{lccccc}
\hline \multicolumn{1}{c}{ Hortaliças } & Umidade & Proteína & Fibra & Cinza & Fração glicídica \\
\cline { 2 - 6 } & & & g.100 g & \\
\hline Abóbora & 88,23 & 1,30 & 1,35 & 0,54 & 8,11 \\
Cenoura & 90,29 & 0,76 & 1,23 & 0,76 & 6,86 \\
Chuchu & 95,39 & 0,15 & 0,40 & 0,40 & 3,44 \\
Mandioquinha-salsa & 76,59 & 1,10 & 0,94 & 0,65 & 20,71 \\
\hline
\end{tabular}

${ }^{1}$ Médias de 3 repetições.
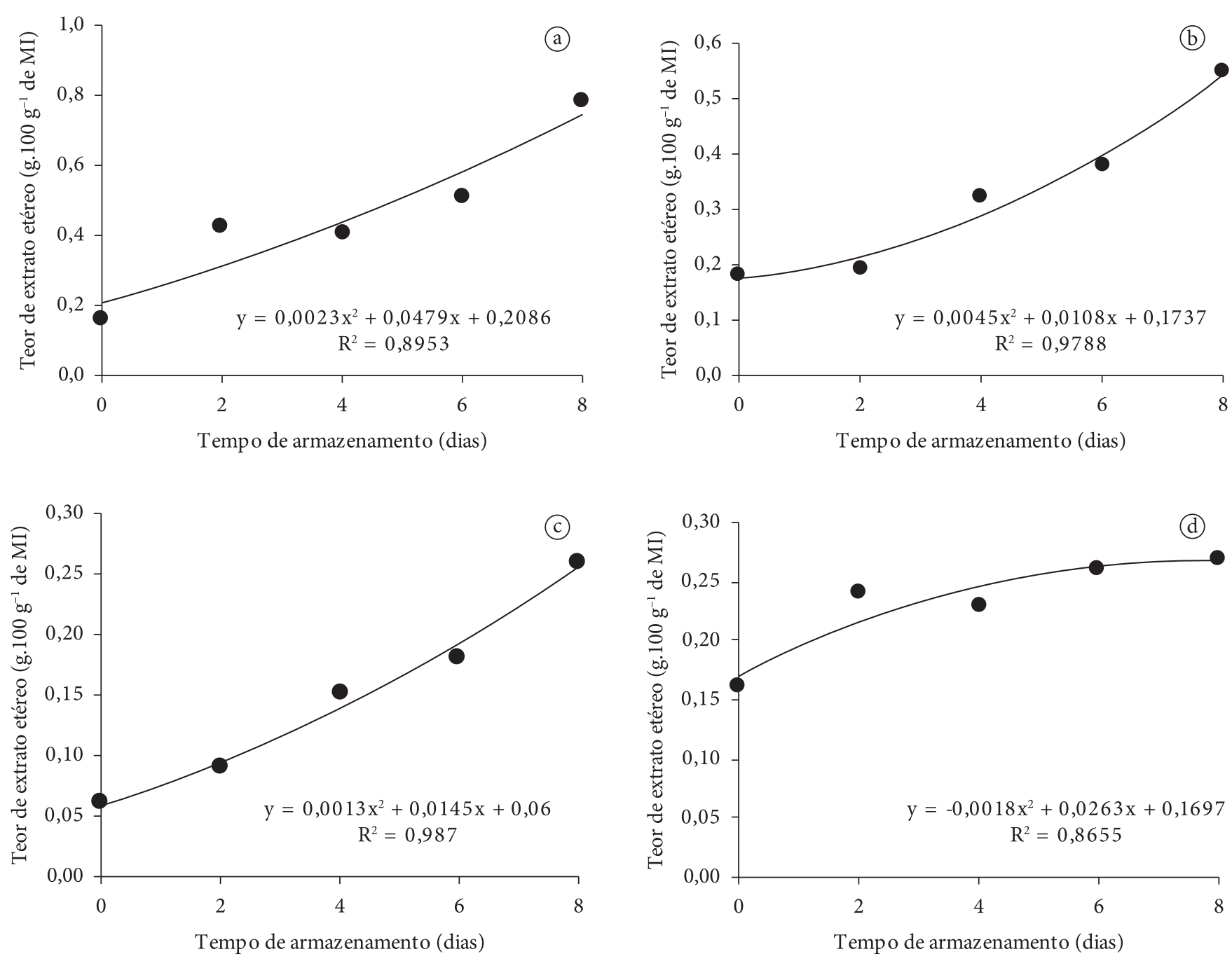

Figura 1. Valores médios, equação de regressão e coeficiente de determinação de extrato etéreo em a) abóbora; b) cenoura; c) chuchu; d) mandioquinha-salsa minimamente processados armazenados a $5{ }^{\circ} \mathrm{C} \pm 1(\mathrm{UR} 90 \% \pm 5)$ por 8 dias. 

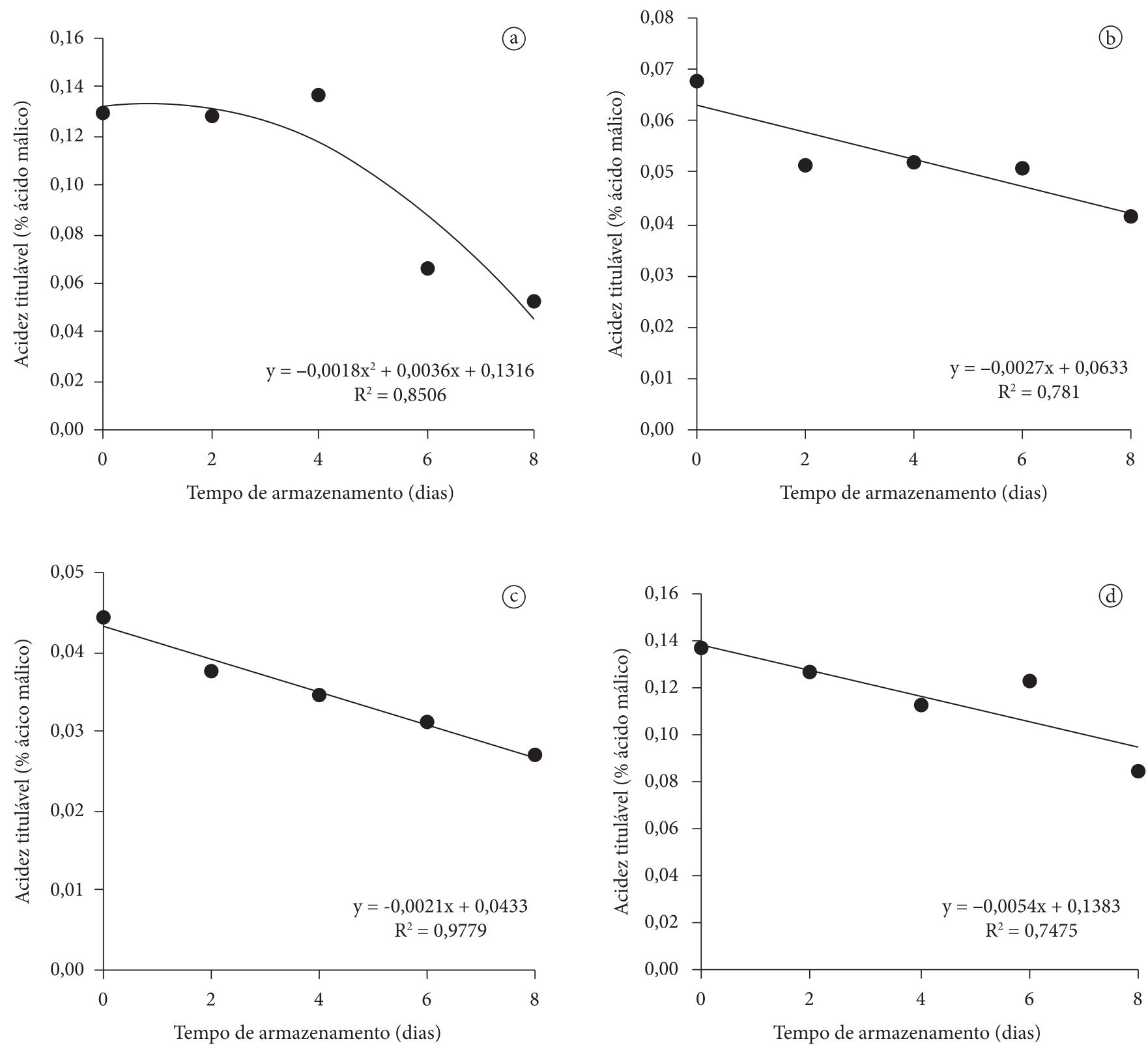

Figura 2. Valores médios, equação de regressão e coeficiente de determinação de acidez titulável em a) abóbora; b) cenoura; c) chuchu; d) mandioquinha-salsa minimamente processados armazenados a $5^{\circ} \mathrm{C} \pm 1(\mathrm{UR} 90 \% \pm 5)$ por 8 dias.

Os valores de $\mathrm{pH}$ da abóbora, cenoura, chuchu e mandioquinha-salsa minimamente processados aumentaram durante o armazenamento, o que pode estar relacionado ao consumo dos ácidos orgânicos pelo processo respiratório. Os valores de $\mathrm{pH}$ variaram de 6,11 a 6,59 na abóbora; 6,23 a 6,79 na cenoura; 6,58 a 7,27 no chuchu e 6,57 a 7,06 na mandioquinhasalsa (Figura 3a, b, c, d).

Pilon (2003) observou um aumento nos valores do $\mathrm{pH}$, de 6,1 a 6,7, em cenoura minimamente processada armazenada a $1{ }^{\circ} \mathrm{C} \pm 1$, por 21 dias - resultados próximos ao encontrados neste trabalho.

Os valores de $\mathrm{pH}$ para o chuchu minimamente processado variaram de 6,58 no tempo zero para 7,27 no oitavo dia de armazenamento. Estes valores de $\mathrm{pH}$ estão pouco acima do encontrado por Oliveira, Srur e Vacari (2003) em chuchu in natura, que foi de 6,35 .

Nunes et al. (2005) observaram em mandioquinha-salsa minimamente processada um valor médio de $\mathrm{pH}$ de 6,79 , que não sofreu influência do tempo de armazenamento. $\mathrm{O}$ valor médio do $\mathrm{pH}$ encontrado neste trabalho $(6,84)$ está muito próximo ao observado por esses autores.

O tempo afetou significativamente $(\mathrm{p}<0,01)$ apenas os teores de sólidos solúveis da cenoura e mandioquinha-salsa. Observouse, ao longo do armazenamento (Figura 4a, b), aumento no teor de sólidos solúveis das cenouras de 11,83\% (5,66 para 6,33 ${ }^{\circ} \mathrm{Brix}$ ) e de $20 \%$ ( 5 para $6{ }^{\circ}$ Brix) para a mandioquinha-salsa. 

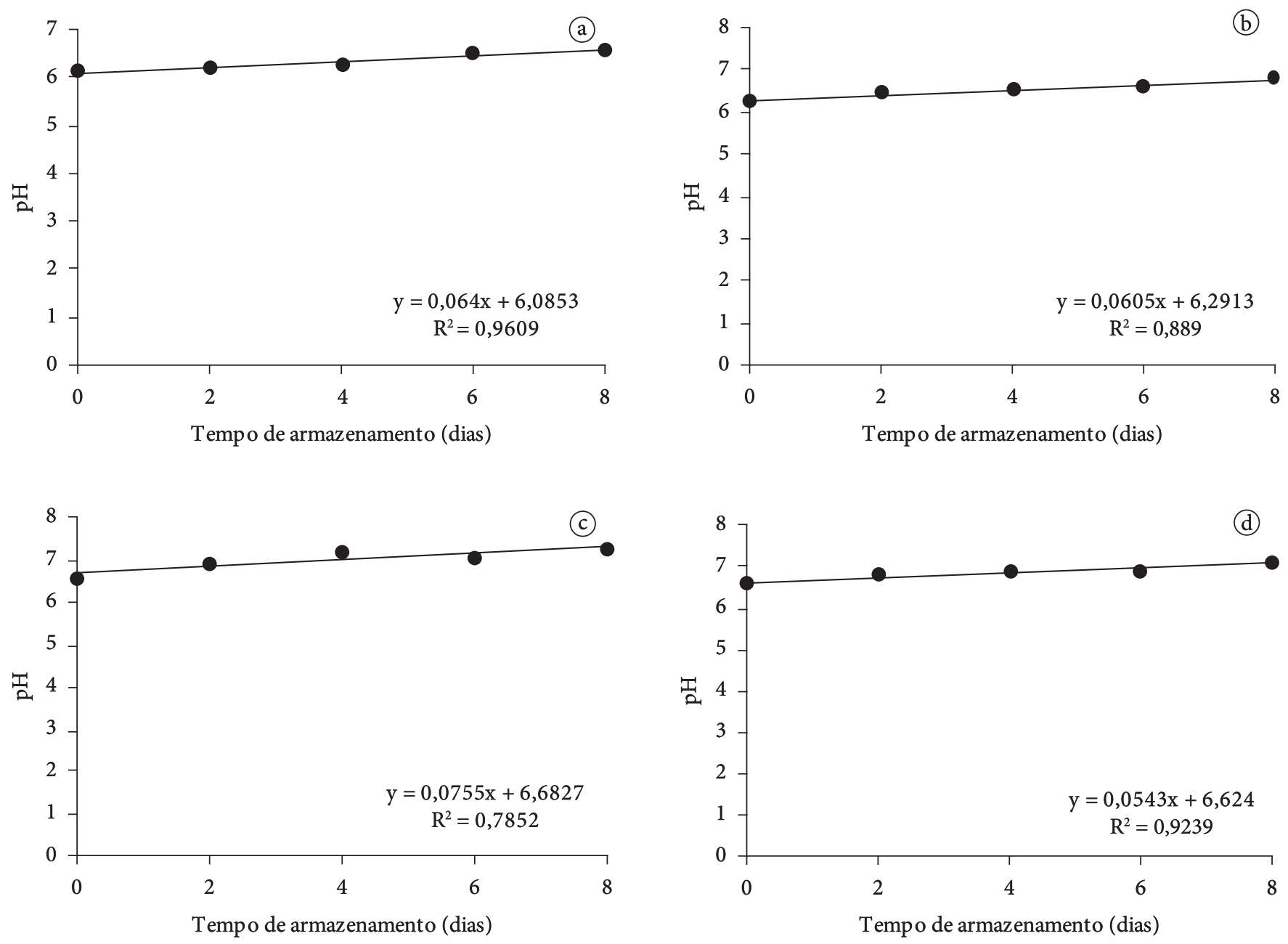

Figura 3. Valores médios, equação de regressão e coeficiente de determinação de pH em a) abóbora; b) cenoura; c) chuchu; d) mandioquinhasalsa minimamente processados armazenados a $5{ }^{\circ} \mathrm{C} \pm 1(\mathrm{UR} 90 \% \pm 5)$, por 8 dias.
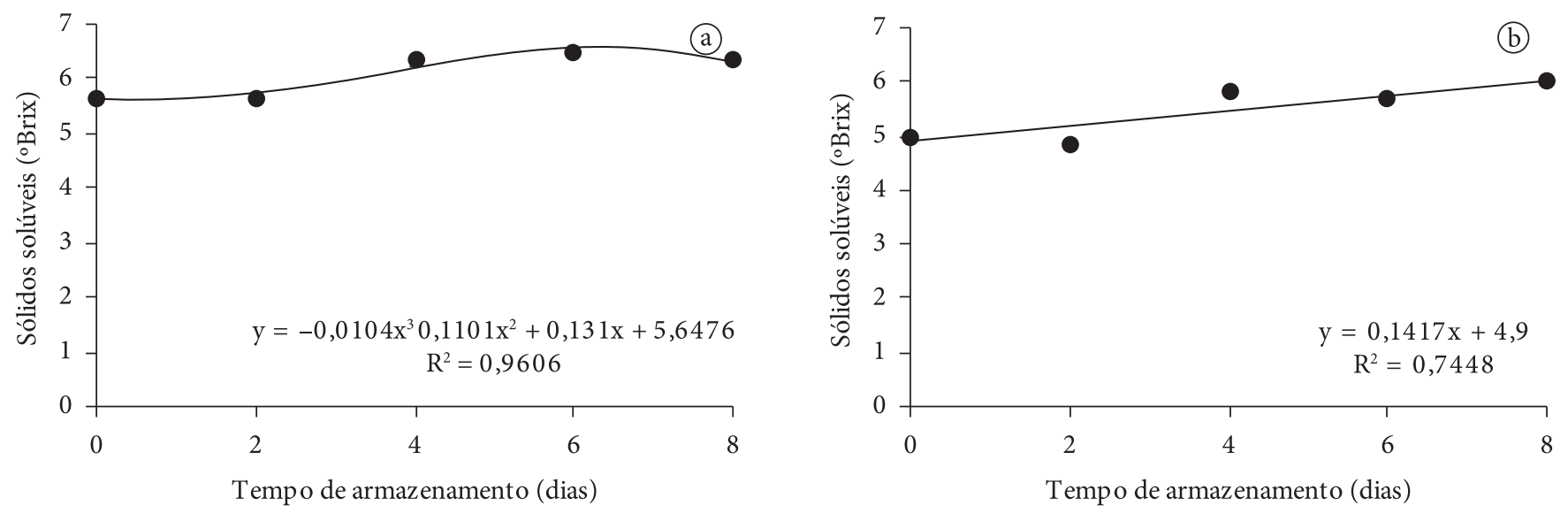

Figura 4. Valores médios, equação de regressão e coeficiente de determinação dos sólidos solúveis em a) cenoura; b) mandioquinha-salsa minimamente processadas armazenadas a $5{ }^{\circ} \mathrm{C} \pm 1(\mathrm{UR} 90 \% \pm 5)$ por 8 dias.

Os teores de sólidos solúveis da abóbora e do chuchu não foram influenciados significativamente $(\mathrm{p}>0,05)$ pelo tempo de armazenamento. Os teores de sólidos solúveis da abóbora foram em média $6,13^{\circ}$ Brix. Sasaki (2005) observou um decréscimo nos teores de sólidos solúveis em abóboras minimamente processadas, armazenadas a $5{ }^{\circ} \mathrm{C}$. Inicialmente era de $5,48^{\circ}$ Brix, chegando a valores de $4,93^{\circ}$ Brix no décimo segundo dia de armazenamento. No chuchu, o teor médio de 
sólidos solúveis encontrado foi de $3,83^{\circ}$ Brix. Valor próximo ao verificado por Oliveira, Srur e Vacari (2003) que foi de $4{ }^{\circ}$ Brix para o chuchu in natura.

Os teores de sólidos solúveis representam boa parte dos açúcares (85 a 90\%) encontrados na maioria dos frutos, sendo o restante constituído de vitaminas, fenólicos, pectinas e ácidos orgânicos. De acordo com Vilas Boas e Lima (1999), o acúmulo de açúcares durante a vida útil dos vegetais pode ocorrer em decorrência da conversão do amido em açúcares. O aumento nos teores dos sólidos solúveis pode vir também da síntese de compostos secundários como fenólicos simples, em resposta às etapas do processamento mínimo (CHITARRA, 2001) e também pelo acúmulo de ácidos orgânicos.

O teor de $\beta$-caroteno da abóbora $(p<0,01)$, da mandioquinha-salsa $(\mathrm{p}<0,01)$ e da cenoura $(\mathrm{p}<0,05)$ foi afetado significativamente pelo tempo de armazenamento. $\mathrm{O}$ teor de $\beta$-caroteno do chuchu não foi afetado estatisticamente $(\mathrm{p}>0,05)$ pelo tempo. De acordo com a Figura $5 \mathrm{a}, \mathrm{b}, \mathrm{c}$, podese observar uma queda nos teores de $\beta$-caroteno da abóbora, cenoura e mandioquinha-salsa seguida de ascendência durante o armazenamento, sugerindo que pode ter ocorrido uma degradação seguida de síntese de $\beta$-caroteno.

O valor médio de $\beta$-caroteno encontrado para a cenoura, foi de $1,25 \mathrm{mg} \cdot 100 \mathrm{~g}^{-1}$. Esse resultado está abaixo dos valores médios encontrados por Pilon (2003), de 2,851 mg. $100 \mathrm{~g}^{-1} \mathrm{e}$ Lima et al. (2004), de 2,60 mg. $100 \mathrm{~g}^{-1}$. A diferença observada nos resultados pode ser atribuída a diferentes metodologias utilizadas para a determinação de $\beta$-caroteno, além do tipo de cultivar, época de colheita, armazenamento e condições edafoclimáticas, às quais a cultura da cenoura foi submetida.

Observou-se efeito significativo do tempo de armazenamento $(\mathrm{p}<0,01)$ para a variável vitamina $\mathrm{C}$, para todas as hortaliças que tiveram o mesmo comportamento, ou seja, ascendência seguida de queda (Figura 6a, b, c, d).

Segundo Chitarra, M. I. F. e Chitarra, A. B. (2005), o teor de vitamina $\mathrm{C}$ tende a diminuir com o armazenamento de muitos produtos hortícolas, devido à atuação direta da
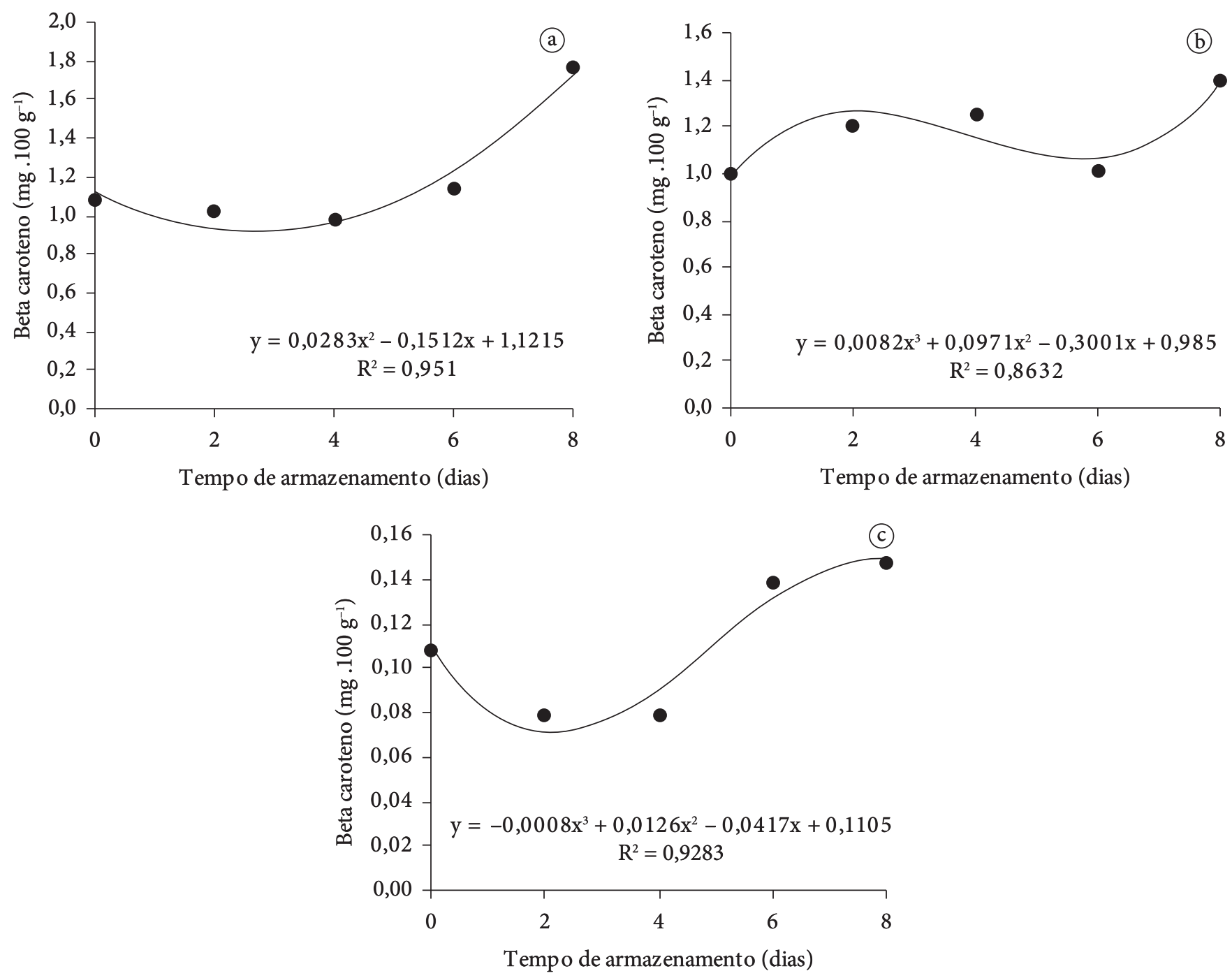

Figura 5. Valores médios, equação de regressão e coeficiente de determinação de $\beta$-caroteno em a) abóbora; b) cenoura; c)mandioquinha-salsa minimamente processadas armazenadas a $5{ }^{\circ} \mathrm{C} \pm 1(\mathrm{UR} 90 \% \pm 5)$ por 8 dias. 
enzima ácido ascórbico oxidase (ascorbinase), ou pela ação de enzimas oxidantes como a peroxidase. Frutas e hortaliças minimamente processadas devem apresentar atributos de qualidade e conveniência do produto fresco. $\mathrm{O}$ teor de vitamina C constitui um importante fator para o controle de qualidade de alimentos e é usado como índice de qualidade nutricional por ser mais sensível à degradação durante o processamento e estocagem em relação a outros nutrientes (ÖZKAN; AYSEGÜL; CEMEROGLU, 2004).

As perdas foram de aproximadamente $24,41 \%$ (variou de 34 para $25,7 \mathrm{mg} .100 \mathrm{~g}^{-1}$ ) em abóbora; 27,59\% (variou de 10,4 para 7,53 mg. $100 \mathrm{~g}^{-1}$ ) em cenoura; $33,48 \%$ (variou de 15,9 para 9,94 mg.100 g $\mathrm{g}^{-1}$ ) em chuchu; e 23,2\% (variou de 30,04 para $23,07 \mathrm{mg} .100 \mathrm{~g} \mathrm{~g}^{-1}$ ) em mandioquinha-salsa. Esse comportamento pode estar relacionado com o processamento mínimo, pois os danos mecânicos causados pelo corte nos tecidos promovem a desorganização celular ocasionando a oxidação do ácido ascórbico.
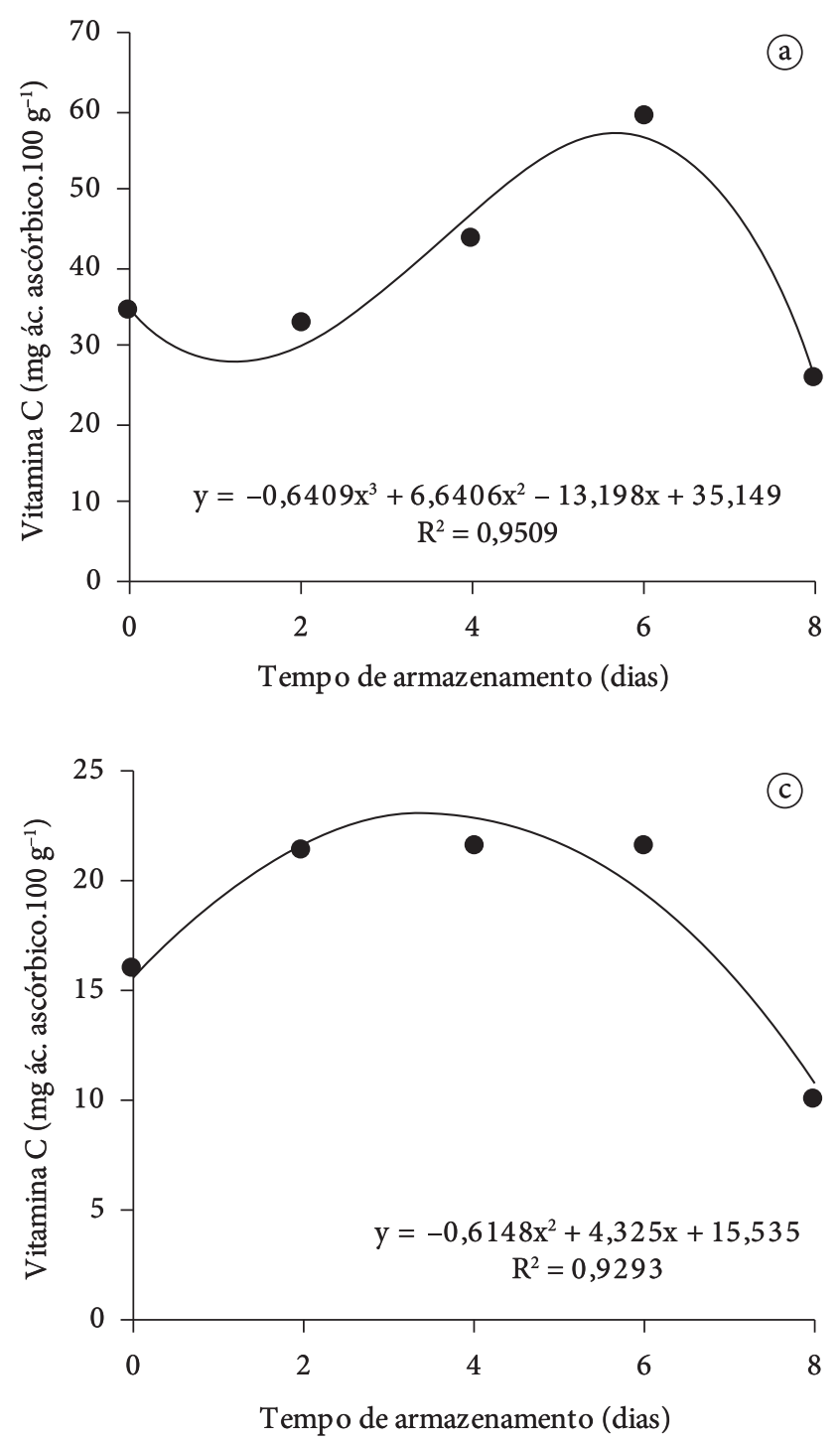

Sasaki (2005) observou também redução nos teores de vitamina $\mathrm{C}$ em abóboras minimamente processadas armazenadas a $5{ }^{\circ} \mathrm{C}$, por 12 dias, alcançando $38,52 \%$ de perdas.

As contagens totais de bactérias em hortaliças são utilizadas como parâmetro da carga microbiana presente, não indicando se a população tem efeito benéfico ou prejudicial. Contudo, servem como um alerta das condições de higiene durante a manipulação e armazenamento, como também dos potenciais riscos oferecidos à saúde do consumidor (BRASIL, 2001; INTERNATIONAL..., 1982).

A legislação brasileira ainda não fixou padrões microbiológicos para os produtos minimamente processados. Portanto os padrões utilizados são aqueles que mais se aproximam de tais alimentos, ou seja, para "hortaliças frescas, refrigeradas, cortadas ou congeladas, para o consumo direto", de acordo com a Resolução RDC n ${ }^{\circ}$ 12 de 02 de janeiro de 2001 da Agência Nacional de Vigilância Sanitária que estipula para Salmonella sp. ausência em $25 \mathrm{~g}$ e de $5 \times 10^{2}$ NMP.g ${ }^{-1}$ para coliformes a $45^{\circ} \mathrm{C}$ (BRASIL, 2001).
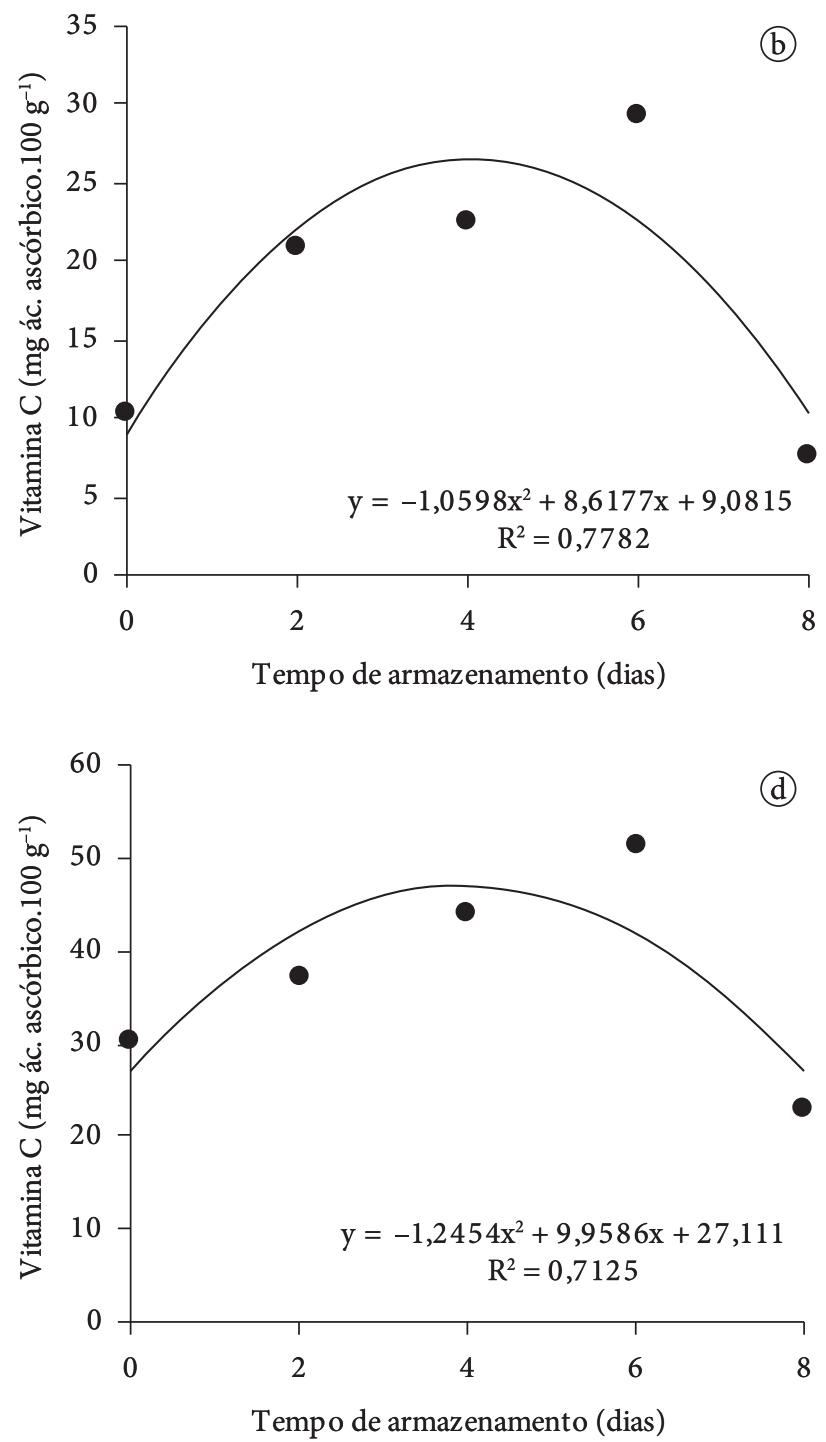

Figura 6. Valores médios, equação de regressão e coeficiente de determinação de vitamina C em a) abóbora; b) cenoura; c) chuchu; d) mandioquinha-salsa minimamente processados armazenados a $5{ }^{\circ} \mathrm{C} \pm 1(\mathrm{UR} 90 \% \pm 5)$ por 8 dias. 
O resultado das análises microbiológicas do produto minimamente processado apontou ausência de Salmonella sp. em $25 \mathrm{~g}$ e valores inferiores a 0,3 NMP.g ${ }^{-1}$ para coliformes a $45^{\circ} \mathrm{C}$, estando de acordo com o estabelecido pela legislação vigente, a RDC n ${ }^{\circ} 12$ (BRASIL, 2001), e verificou-se ausência de Echerichia coli. Apenas os coliformes a $35^{\circ} \mathrm{C}$ apresentaram ligeiro crescimento durante o período de armazenamento.

$\mathrm{Na}$ observação dos resultados para coliformes a $45^{\circ} \mathrm{C}$, reforçou-se a ideia de que a pequena contaminação encontrada para coliformes a $35^{\circ} \mathrm{C}$ não é decorrente de manipulação inadequada ou equipamentos/utensílios mal higienizados, ou seja, não se trata de uma contaminação de origem fecal, pois em todas as amostras estudadas foram encontradas contagens de coliformes $45^{\circ} \mathrm{C}$ inferior a $0,3 \mathrm{NMP.g}{ }^{-1}$.

Pilon (2003) também obteve resultados semelhantes em cenouras minimamente processadas em que observou ausência de coliformes a $45^{\circ} \mathrm{C}$ e Salmonella sp. durante todo o período de armazenamento. Resultado esse concordante com o encontrado neste trabalho para o "mix" de hortaliças minimamente processadas.

Houve efeito significativo do tempo de armazenamento $(\mathrm{p}<0,01)$ sobre a variável aparência. De acordo com a Figura 7 , observou-se decréscimo nas notas atribuídas à aparência do "mix" de hortaliças minimamente processadas. Entretanto, pode-se observar que, durante todo o período de armazenamento, as notas não foram inferiores a 7 (gostei moderadamente), mostrando a aceitação do produto por parte dos provadores.

Segundo Deliza (2000), a aparência do produto exerce papel fundamental na decisão de compra do consumidor, uma vez que é por meio da observação deste parâmetro que o consumidor seleciona, escolhe e consome o alimento.

A aceitabilidade de um alimento pelos consumidores se dá principalmente por sua aparência. O produto minimamente processado à base de hortaliças obteve boa aceitação até o quarto dia de armazenamento (Tabela 2), quando apresentou um declínio, mas, mesmo assim, se manteve em bons níveis de aceitabilidade, indicado pela intenção de compra do produto. Ao longo do armazenamento, não houve recusa de nenhum dos provadores.

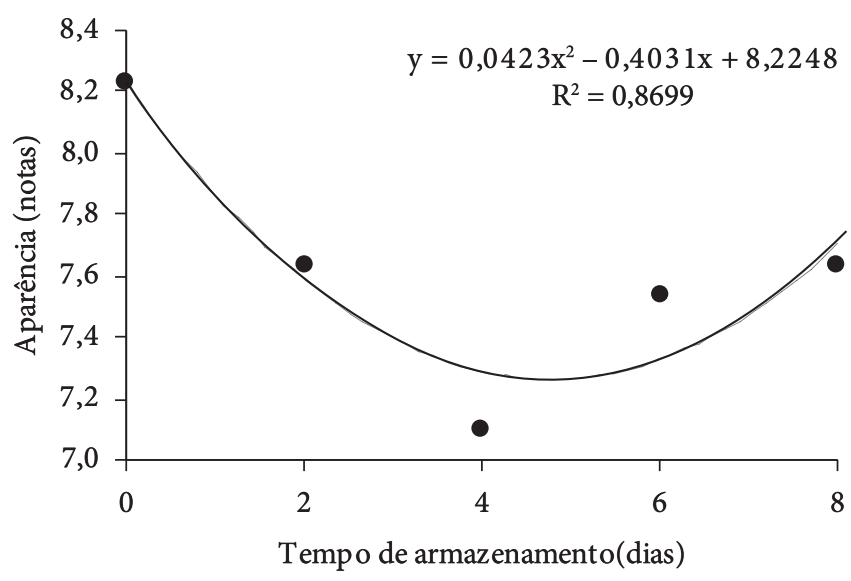

Figura 7. Valores médios, equação de regressão e coeficiente de determinação de aparência do "mix" de hortaliças minimamente processadas armazenadas a $5^{\circ} \mathrm{C} \pm 1(\mathrm{UR} 90 \% \pm 5)$ por 8 dias.
Tabela 2. Resultado do teste de aceitabilidade (intenção de compra) de produto minimamente processado de um total de 30 provadores expresso em \%.

\begin{tabular}{|c|c|c|c|c|c|}
\hline & \multicolumn{5}{|c|}{ Tempo de armazenamento (dias) } \\
\hline & $0(\%)$ & $2(\%)$ & $4(\%)$ & $6(\%)$ & $8(\%)$ \\
\hline $\begin{array}{l}\text { Certamente eu } \\
\text { compraria }\end{array}$ & 41,176 & 34,482 & 33,333 & 32,142 & 31,25 \\
\hline $\begin{array}{l}\text { Provavelmente eu } \\
\text { compraria }\end{array}$ & 35,29 & 24,134 & 13,333 & 28,57 & 56,25 \\
\hline $\begin{array}{l}\text { Talvez eu compraria/ } \\
\text { talvez não compraria }\end{array}$ & 17,647 & 27,586 & 43,333 & 25 & 12,5 \\
\hline $\begin{array}{l}\text { Provavelmente não } \\
\text { compraria }\end{array}$ & 5,88 & 13,793 & 10 & 14,285 & 0 \\
\hline $\begin{array}{l}\text { Certamente eu não } \\
\text { compraria }\end{array}$ & 0 & 0 & 0 & 0 & 0 \\
\hline
\end{tabular}

\section{Conclusões}

De acordo com os resultados, pode-se concluir que a vida útil, entendida sob os aspectos nutricionais, sensoriais e microbiológicos, pode ser estabelecida em 8 dias sob refrigeração a $5{ }^{\circ} \mathrm{C}$ para abóbora, cenoura, chuchu e mandioquinha-salsa submetidos ao processamento mínimo.

\section{Referências bibliográficas}

ASSOCIATION OF OFFICIAL ANALYTICAL CHEMISTS - AOAC. Official methods of analysis of analysis of association of official analytical chemists. 18 ed. Maryland, 2005.

BRASIL. Ministério da Saúde. Agencia Nacional de Vigilância Sanitária. Resolução $\mathbf{n}^{\circ}$ 12, de 02 de janeiro de 2001. Regulamento técnico sobre os padrões microbiológicos para alimento. Disponível em: $<$ http://www.anvisa.gov.br/legis/resol/12_01rdc.htm>. Acesso em: 15 out. 2007.

BRODY, A. L. Envasado de alimentos em atmosferas controladas, modificadas y vazio. Zaragoza: Acribia, 1996. 220 p.

CANTWELL, M. I.; SUSLOW, T. V. Postharvest handling systems: fresh-cut fruits and vegetables. In: KADER, A. A. (Ed.). Postharvest technology of horticultural crops. 3 ed. Davis, California: [s.n.], 2002. cap. 36, p. 445-463.

CHITARRA, M. I. F. Alimentos minimamente processados. Lavras: UFLA/FAEPE, 2001.93 p.

CHITARRA, M. I. F.; CHITARRA, A. B. Pós-colheita de frutas e hortaliças: fisiologia e manuseio.2. ed. rev. e ampl. Lavras: UFLA, 2005. $785 \mathrm{p}$.

DELIZA, R. Importância da qualidade sensorial em produtos minimamente processados. In: ENCONTRO NACIONAL SOBRE PROCESSAMENTO DE FRUTAS E HORTALIÇAS, 2., 2000, Viçosa. Palestras... Viçosa: UFV, 2000. p. 73-74.

DOWNES, F. P.; ITO, K. Compendium of methods for the microbiological examination of foods. 4 ed. Washington, DC: American Public Health Association, 2001. 676 p.

FERREIRA, D. F. Análises estatísticas por meio do SISVAR para windows versão 4.0. In: REUNIÃO ANUAL DA REGIÃO BRASILEIRA DA SOCIEDADE. INTERNACIONAL DE BIOMETRIA, 45., 2000, São Carlos. Programa e Resumos... São Carlos: UFSCar, 2000. p. 235.

INSTITUTO ADOLFO LUTZ - IAL. Normas analíticas, métodos químicos e físicos para análise de alimentos. 3 ed. São Paulo, 1985. v. 1, 533 p. 
INTERNATIONAL COMMISSION ON MICROBIOLOGICAL SPECIFICATIONS FOR FOODS - ICMSF. Microorganisms in foods. 2. ed. Toronto: University of Toronto, 1982. $436 \mathrm{p}$.

INTERNACIONAL FRESH-CUT PRODUCE ASSOCIATION - IFPA. 2007. Disponível em: <http://www.fresh-cuts.org >. Acesso em: 15 jan. 2007.

LIMA, K. S. C. et al. Efeito da irradiação ionizante $\gamma$ na qualidade pós-colheita de cenouras (Daucus carota L.) cv. Nantes. Ciência e Tecnologia de Alimentos, v. 21, n. 2, p. 202-208, maio/ago., 2001.

LIMA, K. S. C. et al. Efeito de baixas doses da irradiação nos carotenóides majoritários em cenouras prontas para o consumo. Ciência e Tecnologia de Alimentos, v. 24, n. 2, p. 183-193, abr./jun, 2004.

LOPES, J. F. et al. A cultura do chuchu. Brasília: EMBRAPA-SPI, 1994. 55 p. (Coleção plantar 14).

NAGATA, M.; YAMASHITA, I. Simple method for simultaneous determination of chlorophyll and carotenoids in tomato fruit. Nippon Shokuhin Kogyo Gakkaishi, v. 39, n. 10, p. 925-928, Oct. 1992.

NUNES, E. E. et al. Efeito da atmosfera modificada na qualidade de mandioquinhas-salsa minimamente processadas. In: CONGRESSO DOS PÓS-GRADUANDOS DA UFLA, 14., 2005, Lavras. Anais... Lavras: APG/UFLA, 2005. 1 CD-ROM

OLIVEIRA, L. F.; SRUR, A. U. O. S.; VACARI, F. Aproveitamento do chuchu (Sechium edule Swartz) pelo processo de saturação com açúcar - uma alternativa alimentar. Revista Universidade Rural, Série Ciências da Vida, v. 22 n. 2, p. 09-14, 2003.

ÖZKAN, M.; AYSEGÜL, K.; CEMEROGLU, B. Effects of hydrogen peroxide on the stability of ascorbic acid during storage in various fruit juices. Food Chemistry, v. 88, n. 4, p. 591-597, Dec. 2004.
PILON, L. Estabelecimento da vida útil de hortaliças minimamente processadas bob atmosfera modificada e refrigeração. 2003. $111 \mathrm{f}$. Dissertação (Mestrado em Ciências)-Escola Superior da Agricultura "Luíz de Queiroz", Universidade de São Paulo, Piracicaba, SP.

SANTOS, F. F dos et al. A cultura da mandioquinha-salsa. Brasília: Empresa Brasileira de Pesquisa Agropecuária, Centro Nacional de Pesquisa de Hortaliças, EMBRAPA-SPI, 1993. 28 p. (Coleção Plantar 3).

SASAKI, F. F. et al. Alterações fisiológicas, qualitativas e microbiológicas durante o armazenamento de abóbora minimamente processada em diferentes tipos de corte. Horticultura Brasileira, v. 24, n. 2, p. 170-174, abr./jun. 2006.

SASAKI, F. F. Processamento mínimo de abóbora (Cucurbita moschata Duch): alterações fisiológicas, qualitativas e microbiológicas. 145 p. Tese (Mestrado)-Escola Superior de Agricultura "Luiz de Queiroz", Universidade de São Paulo, Piracicaba, 2005.

STROHECKER, R.; HENNING, H. M. Analisis de vitaminas: métodos comprobados. Madrid: Paz Montalvo, 1967. 428 p.

UNIVERSIDADE DE SÃO PAULO - USP. Tabela brasileira de composição de alimentos. 2001. Disponível em: <http://www.fcf. usp.br/tabela/tbcamenu.php >. Acesso em: 23 jan. 2007.

VILAS BOAS, E. V. B.; LIMA, L. C. O. Armazenamento de abacaxi 'Pérola'. In: SIMPÓSIO LATINO AMERICANO DE CIÊNCIA DOS ALIMENTOS, 3. Resumos... Campinas: UNICAMP, 1999. p. 45.

von de KAMER, S. B.; van GINKEL, L. Rapid determination of crude fiber in cereals. Cereal Chemistry, v. 19, n. 4, p. 239-251, July-Aug. 1952. 